\title{
Survival outcome and prognostic factor analyses in early tongue cancer patients treated with surgery alone
}

\author{
Hao-Shen Cheng ${ }^{1}$, Shih-An Liu ${ }^{2}$, Jin-Ching $\operatorname{Lin}^{1,3}$ \\ ${ }^{1}$ Department of Radiation Oncology, ${ }^{2}$ Department of Otorhinolaryngology, Taichung Veterans General Hospital, Taichung City, Taiwan; \\ ${ }^{3}$ Department of Radiation Oncology, Changhua Christian Hospital, Changhua City, 500, Taiwan \\ Contributions: (I) Conception and design: All authors; (II) Administrative support: JC Lin; (III) Provision of study material or patients: SA Liu; (IV) \\ Collection and assembly of data: HS Cheng; (V) Data analysis and interpretation: All authors; (VI) Manuscript writing: All authors; (VII) Final \\ approval of manuscript: All authors. \\ Correspondence to: Jin-Ching Lin, MD, PhD. Department of Radiation Oncology, Changhua Christian Hospital, 135 Nanxiao St., Changhua City, \\ 500, Taiwan. Email: jinchinglin@gmail.com.
}

Background: The long-term outcome for early stage tongue cancer is generally good, however patients who suffered from local recurrence experienced a worse outcome than those who had not. The purpose of this study was to analyze long-term outcome for early stage tongue cancer patients treated by surgery alone for potential factors in predicting any subsequent relapse.

Methods: The inclusion criteria for this retrospective study involved previously untreated, biopsy-proven squamous cell carcinoma (SCC) of the tongue, clinical stage T1-2N0M0 and patients who had received surgery alone. From February 2007 to January 2015, the chart records and images of 199 eligible patients were reviewed.

Results: After a medial follow-up period of 89 months, we discovered 53 recurrences and 34 deaths. The 5-year overall survival (OS) and locoregional failure-free survival (LRFFS) rates were 83.9\% and 72.4\%, respectively. Univariate and multivariate analyses revealed that a poorly differentiated histology, depth of invasion (DOI) $>5 \mathrm{~mm}$, and perineural invasion (PNI) affected both OS and LRFFS. Patients with an absence of any risk factors (poorly differentiated histology, invasion depth over $5 \mathrm{~mm}$, and PNI) experienced significantly better OS (5-year rates, $92.0 \%$ vs. $72.7 \%, \mathrm{P}=0.0001$ ) and LRFFS (5-year rates, $76.8 \%$ vs. $66.6 \%$, $\mathrm{P}=0.0382$ ) than those with at least one of the risk factors.

Conclusions: An overall relapse rate of $26.6 \%$ was observed for patients with early tongue cancer treated by surgery alone. Patients with risk factors (poorly differentiated histology, DOI $>5 \mathrm{~mm}$, and PNI) should be considered for postoperative adjuvant therapy in future trials.

Keywords: Early tongue cancer; recurrence; prognostic factors

Received: 28 August 2019; Accepted: 13 January 2020; Published: 30 June 2020.

doi: $10.21037 /$ tro.2020.01.02

View this article at: http://dx.doi.org/10.21037/tro.2020.01.02

\section{Introduction}

Squamous cell carcinoma (SCC) of the oral cavity is a commonly found cancer around the world, with an estimated 300,000 new cases per year (1). The primary treatment for patients with early stage SCC of the oral cavity is surgery, whereas postoperative adjuvant treatment is indicated for stages III-IV of the disease (2). SCC arising from the oral cavity includes several different subsites, such as the tongue, buccal mucosa, gingiva, floor of the mouth, and hard palate, along with others. Amongst them, tongue cancer is the one most frequently seen. The long-term outcome for early tongue cancer (T1-2N0M0) is generally good, with 5-year Overall Survival (OS) rates between $75 \%$ and $89 \%(3-5)$. However, some patients suffer from local recurrence, and the prognosis for this subgroup is always 
worse than those who do not experience local recurrence (6).

There are several pathological factors reported to have influence on recurrence. Shim et al. reported that a higher tumor grade (moderate to poor differentiation), and a depth of invasion (DOI) $\geq 5 \mathrm{~mm}$ were the significant prognostic factors affecting OS and disease free survival (DFS) (3). Fridman et al. found out that close $(<5 \mathrm{~mm})$ and positive margins could affect OS, and were even associated with a $>2$-fold increase in the risk of recurrence (7). DOI, tumor budding and Worst Pattern Of Invasion (WPOI) were reported by Almangush et al. to be predictors for OS (8); while DOI and WPOI were further recognized as strong pathological predictors for locoregional recurrence (9). Additionally, certain minor adverse features such as lymphovascular invasion (LVI), and perineural invasion (PNI), were also reported to cause worse locoregional control (10-12).

The purpose of this study was to analyze long-term outcome in patients with early tongue SCC treated by surgery alone. We also performed prognostic factor analyses and searched for any potential factors in predicting subsequent relapse.

\section{Methods}

The inclusion criteria of this retrospective study involved patients with previously untreated, pathologically-proved SCC of the tongue, clinical stage T1-2N0M0, and who had received surgery alone at our hospital. Patients who had received Postoperative Radiotherapy (PORT) were excluded. From the cancer registration databank of our hospital, we enrolled 199 eligible patients from 2007 to 2014. We performed a thorough review of each patient's hospital charts and image files. The relapse rate, OS and locoregional failure-free survival (LRFFS) of the entire subject population was analyzed. OS was defined as the time between the day of surgery and the date of death or last contact. LRFFS was defined as the time between the day of surgery to the date of local, regional or locoregional recurrences detected, or the date of last clinical follow up. The OS and LRFFS were calculated using the KaplanMeier method. Survival differences between the different subgroups were analyzed using the log-rank test. We further investigated prognostic factors influencing survival through univariate and multivariate analyses using the Cox proportional-hazards model. All statistical analyses were performed with SPSS 23 (IBM Co., New York, United States). A P value less than 0.05 was considered statistically significant. This retrospective study was approved by the Institutional Review Board of our hospital and informed consent was waived.

\section{Results}

After a median follow-up period of 89 months, there were 53 recurrences (local alone in 18 cases, regional alone in 26, local plus distant metastasis in 3 , and regional plus distant metastasis in 6), along with 34 deaths. Patient baseline characteristics are summarized in Table 1 . The 5-year rates of OS and LRFFS for all 199 patients were $83.9 \%$ and $72.4 \%$, respectively (Figure 1 ).

The results of univariate and multivariate analyses for OS and LRFFS are summarized in Tables 2 and 3. Briefly, univariate analysis revealed that a poorly differentiated histology $(\mathrm{P}=0.0099)$, DOI $>5 \mathrm{~mm}(\mathrm{P}=0.0028)$, tumor size over $2 \mathrm{~cm}(\mathrm{P}=0.0001)$, along with $\mathrm{PNI}(\mathrm{P}=0.0049)$ significantly affected OS. Similarly, a poorly differentiated histology $(\mathrm{P}=0.0001), \mathrm{DOI}>5 \mathrm{~mm}(\mathrm{p}=0.0839)$, and PNI $(\mathrm{P}=0.0721)$ also affected LRFFS. Multivariate analysis showed that a poorly differentiated histology $(\mathrm{P}=0.0119)$ and tumor size over $2 \mathrm{~cm}(\mathrm{P}=0.0056)$ were independent predictors for OS, but only a poorly differentiated histology $(\mathrm{P}<0.0001)$ could predict LRFFS. Of note, a close resection margin was frequently reported as a negative indicator of both recurrence and survival. Our results revealed no significant impacts of close margin $(\leq v s .>3 \mathrm{~mm})$ on LRFFS and OS by either univariate or multivariate analyses. On the other hand, we performed a subgroup analysis in patients with a tumor size $>2 \mathrm{~cm}$ or DOI $>5 \mathrm{~mm}$, and found that END becomes influential to OS $(\mathrm{P}=0.0994)$ in the subgroup.

Finally, we selected the following three variablesa poorly differentiated histology, DOI $>5 \mathrm{~mm}$ and PNI as being the risk factors in predicting overall survival and locoregional recurrence. Re-grouping analyses with the Kaplan-Meier method found that patients with an absence of any risk factors experienced significantly better OS (5-year rates, $92.0 \%$ vs. $72.7 \%, \mathrm{P}=0.0001$ ) and LRFFS (5-year rates, $76.8 \%$ vs. $66.6 \%, \mathrm{P}=0.0382$ ) than those with the presence of at least one risk factor (Figure 2). A Cox proportionalhazards model also confirmed the same results in OS and LRFFS (see Table 4). 
Table 1 Patient demographic and baseline characteristics (n=199)

\begin{tabular}{|c|c|c|}
\hline Characteristics & No. of cases & Percent \\
\hline \multicolumn{3}{|l|}{ Age (years) } \\
\hline Range & $27-86$ & \\
\hline Median & 52 & \\
\hline Mean & 52 & \\
\hline$<50$ & 78 & 39.2 \\
\hline$\geq 50$ & 121 & 60.8 \\
\hline \multicolumn{3}{|l|}{ Gender } \\
\hline Male & 165 & 82.9 \\
\hline Female & 34 & 17.1 \\
\hline \multicolumn{3}{|l|}{ Smoking } \\
\hline Quit or non-smoker & 66 & 33.1 \\
\hline Current smoker & 133 & 66.9 \\
\hline \multicolumn{3}{|c|}{ Elective neck dissection } \\
\hline Yes & 103 & 51.8 \\
\hline No & 96 & 48.2 \\
\hline \multicolumn{3}{|l|}{ Differentiation } \\
\hline Well \& moderate & 174 & 87.4 \\
\hline Poor & 25 & 12.6 \\
\hline \multicolumn{3}{|l|}{ Depth of invasion } \\
\hline$\leq 5 \mathrm{~mm}$ & 145 & 72.9 \\
\hline$>5 \mathrm{~mm}$ & 54 & 27.1 \\
\hline \multicolumn{3}{|l|}{ Tumor size } \\
\hline$\leq 2 \mathrm{~cm}$ & 166 & 83.4 \\
\hline$>2 \mathrm{~cm}$ & 33 & 16.6 \\
\hline \multicolumn{3}{|l|}{ Closest margin } \\
\hline$>3 \mathrm{~mm}$ & 135 & 67.8 \\
\hline$\leq 3 \mathrm{~mm}$ & 64 & 32.2 \\
\hline \multicolumn{3}{|c|}{ Lymphovascular invasion } \\
\hline Negative & 197 & 99.0 \\
\hline Positive & 2 & 1.0 \\
\hline \multicolumn{3}{|l|}{ Perineural invasion } \\
\hline Negative & 185 & 93.0 \\
\hline Positive & 14 & 7.0 \\
\hline
\end{tabular}

\section{Discussion}

Patients diagnosed with early stage oral tongue cancer are believed to have a good prognosis. Shim et al. reported that the 5-year OS and DFS of T1-2N0-1 tongue SCC was $80.8 \%$ and $80.2 \%$, respectively (3). On the other hand, Ganly et al. reported that the 5-year OS and Relapse Free Survival (RFS) rates were $79 \%$ and $70 \%$ respectively, in T1-2N0 oral tongue cancer (5). An additional retrospective study based on the American Surveillance, Epidemiology, and End Results (SEER) database identified 6,791 patients with stage I and II SCC of the oral cavity, reported that the five-year cause-specific survival rates of stage I and II oral tongue cancers to be $83.5 \%$ (13). Our results (5-year OS $=83.9 \%$ and LRFFS $=72.4 \%$ ) are compatible with previous studies.

In our study, the DOI had a tendency to influence LRFFS $(\mathrm{P}=0.0839)$, but not in any significant manner. The reason for this may be the relatively small case numbers in the DOI $>5 \mathrm{~mm}(\mathrm{n}=54)$ group. Overall, our data supports that a poorly differentiated histology, DOI over $5 \mathrm{~mm}$ and PNI have adverse impacts on both OS and LRFFS. Thus, postoperative adjuvant treatment could be considered for these patients in the future. Katz et al. reported that adjuvant radiotherapy can improve disease-free survival for patients with minor adverse factors (perivascular invasion, PNI, poor differentiation, DOI $>5 \mathrm{~mm}$ and a close margin between 1 to $5 \mathrm{~mm}$ ) (12). In contrast, Rajappa et al. found that the addition of adjuvant radiotherapy based upon the depth of invasion does not influence survival in patients diagnosed with early carcinoma of the tongue (14). Considering the potential risk of long-term complications for adjuvant radiotherapy, we will need to design a prospective study in order to investigate the definitive role of PORT for the treatment of early tongue cancer.

The margin status ( $>3 v s . \leq 3 \mathrm{~mm}$ ) did not affect either OS or LRFFS in our study. A similar result was reported in a retrospective study of 200 patients (15). That study reported that avoiding local adjuvant treatment in cases of close margins $>3 \mathrm{~mm}$, with $\leq 2$ unfavorable histological parameters (spidery infiltrative growth, peri-neural or vascular invasive growth) is acceptable. No consensus regarding the necessity of adjuvant treatment to close margins exist. Some authors have stated that surgical margin conditions have an impact on both local recurrence and OS (16,17), while others found the opposite result to be true (18). No prospective randomized clinical trials are yet available to address this issue, with most studies having 

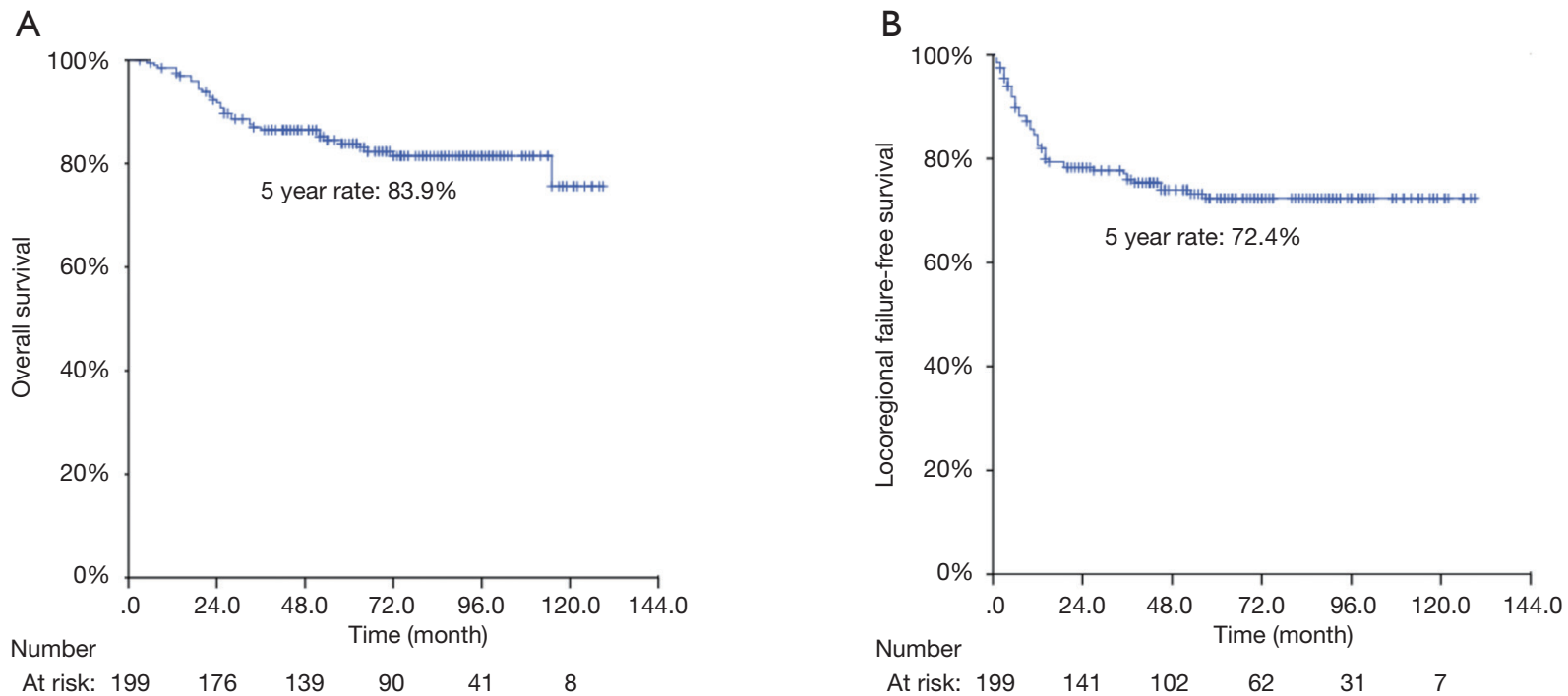

Figure 1 Kaplan-Meier survival analysis for all 199 patients: overall survival (A) and locoregional failure-free survival (B).

a retrospective design. Because of the low numbers of local recurrences in early tongue cancer patients, definitive conclusions are difficult to make. According to our study, the close margin of $\leq 3 \mathrm{~mm}$ seems irrelevant when making decisions on adjuvant treatment for early oral tongue cancers.

Lymphovascular invasion was also shown to have no significant influence on survival in our study. The reason for this could be the imbalance in the distribution of our study group. One hundred ninety-seven patients experienced no LVI, while only 2 patients had. In the subgroup of patients with END, LVI became a significant factor to local-regional recurrence $(\mathrm{P}=0.0013)$. Because of the extremely small number of patients who had experienced LVI (2/199), we found no statistical meaning with regards to this situation.

Elective neck dissection (END) is another controversial issue when discussing early tongue cancer. The lymphatic system of the oral tongue offers extensive communication across the midline, giving SCC of the oral tongue a high possibility to metastasize bilaterally. The regional recurrence rate for untreated N0 necks was found to be between $30 \%$ and $47 \%$ for early oral cavity cancer (19), when led the studies toward the use of elective neck dissection. D'Cruz et al. performed a prospective randomized controlled trial, enrolling 596 patients with T1 or T2 oral SCC between 2004 and 2014. They concluded that elective neck dissection improved both OS and DFS (20). A systematic review in 2019 (21) showed that END can decrease recurrence and improve DFS, OS and disease-specific survival for patients with early-stage SCC of the oral cavity. In cT1N0M0 subgroup analysis, END could significantly reduce neck recurrence and improve DFS, however the difference between OS and DSS did not achieve any level of significance. At our hospital, the decision as to whether or not END should be performed is mainly based upon each surgeon's experience. The chi-square test showed that END was performed more frequently in patients with a tumor size above $2 \mathrm{~cm}(\mathrm{P}=0.0002)$. In our study, END did not influence OS and LRFFS significantly. Interestingly, END became influential to OS $(\mathrm{P}=0.0994)$ in the subgroup with a tumor size $>2 \mathrm{~cm}$ or DOI $>5 \mathrm{~mm}$. It is reasonable to concluded that END may be benefit to patients with a tumor size $>2 \mathrm{~cm}$ or DOI $>5 \mathrm{~mm}$. Having $68.8 \%$ $(137 / 199)$ of patients in our study diagnosed with a tumor size $\leq 2 \mathrm{~cm}$ and DOI $\leq 5 \mathrm{~mm}$, could be the reason why our analysis showed that END was not a significant prognostic factor. Neck dissection may lead to complications such as shoulder pain and dysfunction, despite offering survival benefits. The prevalence of a reduced active neck range of motion after neck dissection was 1-13\% (22). Careful selection of patients for performing an END should be done, and END may be passed over when the tumor size $\leq 2 \mathrm{~cm}$, and combined with DOI $\leq 5 \mathrm{~mm}$. More prospective 
Table 2 Overall survival analyses using Cox proportional hazards model ( $\mathrm{n}=199)$

\begin{tabular}{|c|c|c|c|c|}
\hline Characteristics & \multicolumn{2}{|c|}{ Univariate } & \multicolumn{2}{|c|}{ Multivariate } \\
\hline \multicolumn{5}{|l|}{ Age (years) } \\
\hline$<50$ vs. $\geq 50$ & $0.9(0.5-1.9)$ & 0.8630 & $0.9(0.4-1.8)$ & 0.6819 \\
\hline \multicolumn{5}{|l|}{ Gender } \\
\hline \multicolumn{5}{|l|}{ Smoking } \\
\hline Quit usage or non-smoker vs. current smoker & $0.7(0.4-1.5)$ & 0.3912 & $1.1(0.5-2.7)$ & 0.8259 \\
\hline \multicolumn{5}{|l|}{ Elective neck dissection } \\
\hline Yes vs. no & $0.9(0.4-1.7)$ & 0.6496 & $1.4(0.6-2.9)$ & 0.4018 \\
\hline \multicolumn{5}{|l|}{ Differentiation } \\
\hline \multicolumn{5}{|l|}{ DOI } \\
\hline$\leq 5$ vs. $>5 \mathrm{~mm}$ & $2.8(1.4-5.5)$ & 0.0028 & $1.6(0.6-3.9)$ & 0.3186 \\
\hline \multicolumn{5}{|l|}{ Tumor size } \\
\hline$\leq 2$ vs. $>2 \mathrm{~cm}$ & $3.9(1.9-7.8)$ & 0.0001 & $3.6(1.5-9.0)$ & 0.0056 \\
\hline \multicolumn{5}{|l|}{ Closest margin } \\
\hline$>3$ vs. $\leq 3 \mathrm{~mm}$ & $1.2(0.6-2.5)$ & 0.5710 & $0.9(0.4-1.9)$ & 0.6930 \\
\hline \multicolumn{5}{|l|}{ Lymphovascular invasion ${ }^{\#}$} \\
\hline Negative vs. positive & - & - & - & - \\
\hline
\end{tabular}

$\mathrm{HR}$, hazard ratio; $\mathrm{Cl}$, confidence interval; DOI, depth of invasion. "indicated no statistical meaning due to extremely unbalanced distribution (197 negative and 2 positive).

studies are required in order to make a solid conclusion, and to define which group of patients would benefit from END. A paradoxical result is one in which END is not significant in univariate analysis for LRFFS, but significant in multivariate analysis. After analyzing the relationships between factors, the composition of the END population is highly related to tumor differentiation and the DOI. Since both tumor differentiation and the DOI influence LRFFS in univariate analysis, this result could be the reason leading to incoherent data being seen in univariate and multivariate analysis.

One of advantages of this study is that most of our patients have been followed for 5 years, allowing us to observe long-term survival and the recurrence patterns. Additionally, we excluded patients who had been treated with adjuvant radiotherapy in order to minimize the mask effect of radiotherapy. One of the limitations of our study is its retrospective design. Also, our intermediate sample size led to the patient numbers in certain subgroups to be too small to provide positive results. Also, budding or WPOI was not routinely reported by the pathologist during the study period, so it is difficult to perform analysis based on these factors.

In conclusion, more than one-fourth early of tongue SCC patients treated by surgery alone develope recurrences. A poorly differentiated histology, DOI $>5 \mathrm{~mm}$ and PNI are the risk factors influencing both OS and LRRFS. Postoperative adjuvant therapy deserves the opportunity to be attempted for patients possessing these risk factors in the future. 

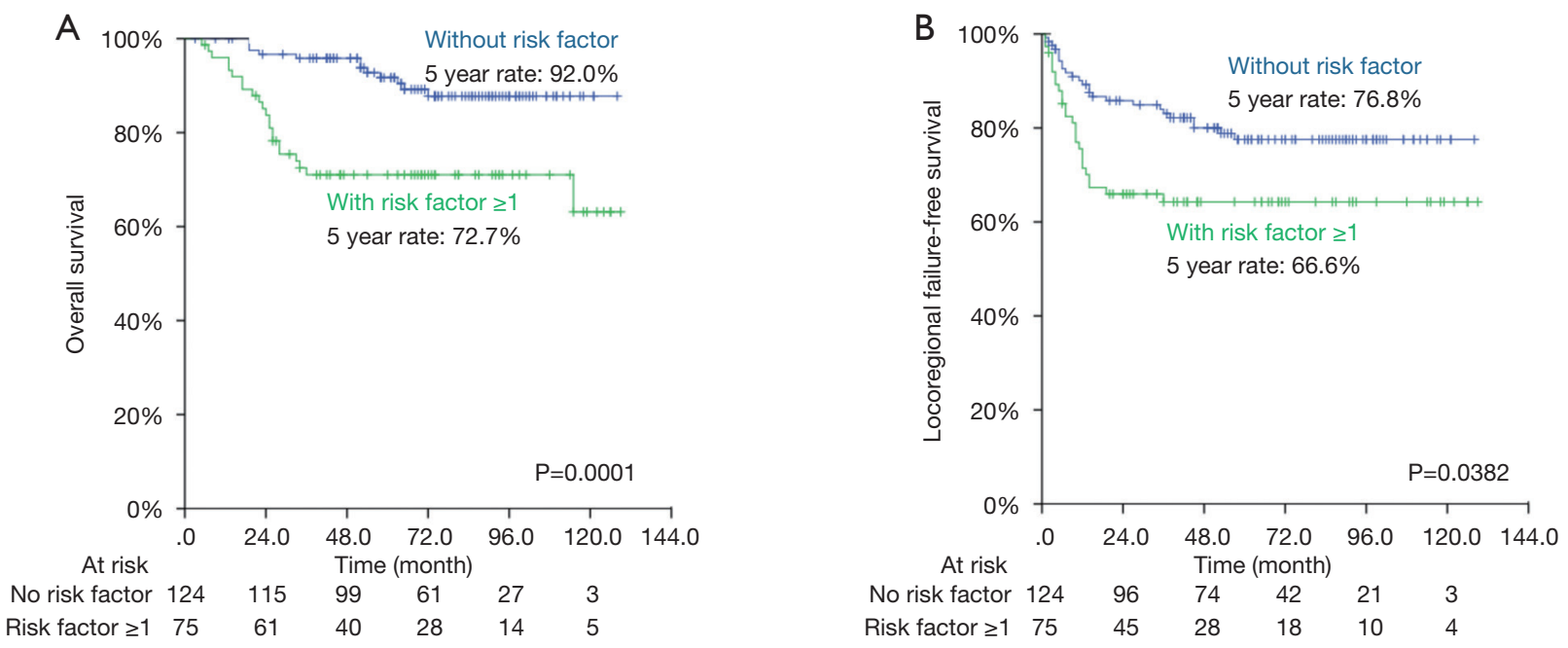

Figure 2 Overall survival (A) and locoregional failure-free survival (B) stratified by the presence/absence of risk factors.

Table 3 Local-regional failure-free survival (LRFFS) analyses using Cox proportional hazards model (n=199)

\begin{tabular}{|c|c|c|c|c|}
\hline \multirow{2}{*}{ Characteristics } & \multicolumn{2}{|c|}{ Univariate } & \multicolumn{2}{|c|}{ Multivariate } \\
\hline & $\mathrm{HR}(95 \% \mathrm{Cl})$ & $P$ value & $\mathrm{HR}(95 \% \mathrm{Cl})$ & $P$ value \\
\hline \multicolumn{5}{|l|}{ Age (years) } \\
\hline$<50$ vs. $\geq 50$ & $0.8(0.5-1.4)$ & 0.4575 & $0.8(0.5-1.4)$ & 0.4848 \\
\hline \multicolumn{5}{|l|}{ Gender } \\
\hline Quit or non-smoker vs. current smoker & $0.8(0.5-1.5)$ & 0.5335 & $0.9(0.4-1.8)$ & 0.7095 \\
\hline \multicolumn{5}{|l|}{ Elective neck dissection } \\
\hline Yes vs. no & $1.4(0.8-2.4)$ & 0.2442 & $1.9(1.1-3.5)$ & 0.0303 \\
\hline$\leq 5$ vs. $>5 \mathrm{~mm}$ & $1.6(0.9-3.0)$ & 0.0839 & $1.6(0.8-3.2)$ & 0.1990 \\
\hline \multicolumn{5}{|l|}{ Tumor size } \\
\hline$\leq 2$ vs. $>2 \mathrm{~cm}$ & $1.5(0.8-2.9)$ & 0.2367 & $1.4(0.6-3.3)$ & 0.4091 \\
\hline \multicolumn{5}{|l|}{ Closest margin } \\
\hline$>3$ vs. $\leq 3 \mathrm{~mm}$ & $1.2(0.7-2.0)$ & 0.5984 & $1.2(0.6-2.2)$ & 0.6274 \\
\hline \multicolumn{5}{|l|}{ Lymphovascular invasion ${ }^{\#}$} \\
\hline Negative vs. positive & - & - & - & - \\
\hline \multicolumn{5}{|l|}{ Perineural invasion } \\
\hline
\end{tabular}

$\mathrm{HR}$, hazard ratio; $\mathrm{Cl}$, confidence interval; DOI, depth of invasion. " indicated no statistical meaning due to extremely unbalanced distribution (197 negative and 2 positive). 
Table 4 Combined analyses (without $v s$. with risk factors) for overall survival and locoregional failure-free survival using Cox proportional hazards model

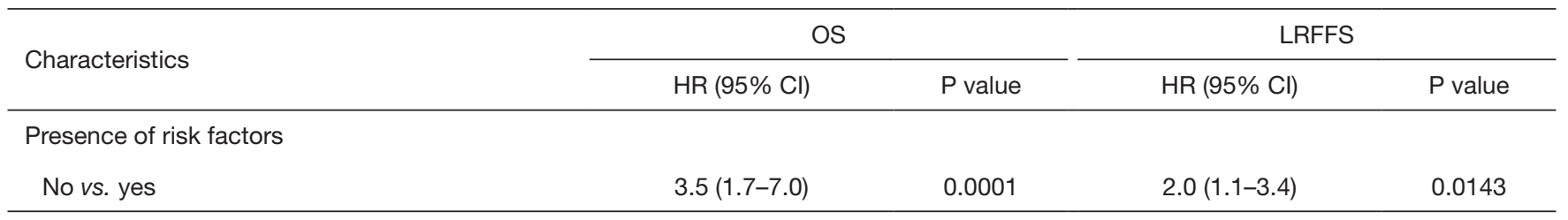

$\mathrm{HR}$, hazard ratio; $\mathrm{Cl}$, confidence interval; OS, overall survival; LRFFS, locoregional failure-free survival.

\section{Acknowledgments}

Funding: None.

\section{Footnote}

Conflicts of Interest: All authors have completed the ICMJE uniform disclosure form (available at http://dx.doi. org/10.21037/tro.2020.01.02). JCL serves as the unpaid editorial board member of Therapeutic Radiology and Oncology from May 2020 to Apr 2022. The other authors have no conflicts of interest to declare.

Ethical Statement: The authors are accountable for all aspects of the work in ensuring that questions related to the accuracy or integrity of any part of the work are appropriately investigated and resolved. The study was conducted in accordance with the Declaration of Helsinki (as revised in 2013). This retrospective study was approved by the local Institutional Review Board (No. CE19030A). All authors are accountable for all aspects of the work. Any conflict of interest does not exist. Informed consent was waived due to the retrospective nature of the study.

Open Access Statement: This is an Open Access article distributed in accordance with the Creative Commons Attribution-NonCommercial-NoDerivs 4.0 International License (CC BY-NC-ND 4.0), which permits the noncommercial replication and distribution of the article with the strict proviso that no changes or edits are made and the original work is properly cited (including links to both the formal publication through the relevant DOI and the license). See: https://creativecommons.org/licenses/by-nc-nd/4.0/.

\section{References}

1. Bray F, Ferlay J, Soerjomataram I, et al. Global cancer statistics 2018: GLOBOCAN estimates of incidence and mortality worldwide for 36 cancers in 185 countries. CA Cancer J Clin 2018;68:394-424.

2. Shah JP, Gil Z. Current concepts in management of oral cancer--surgery. Oral Oncol 2009;45:394-401.

3. Shim SJ, Cha J, Koom WS, et al. Clinical outcomes for T1-2N0-1 oral tongue cancer patients underwent surgery with and without postoperative radiotherapy. Radiat Oncol 2010;5:43.

4. Al-Rajhi N, Khafaga Y, El-Husseiny J, et al. Early stage carcinoma of oral tongue: prognostic factors for local control and survival. Oral Oncol 2000;36:508-14.

5. Ganly I, Patel S, Shah J. Early stage squamous cell cancer of the oral tongue--clinicopathologic features affecting outcome. Cancer 2012;118:101-11.

6. Yanamoto S, Yamada S, Takahashi H, et al. Predictors of locoregional recurrence in T1-2N0 tongue cancer patients. Pathol Oncol Res 2013;19:795-803.

7. Fridman E, Na'ara S, Agarwal J, et al. The role of adjuvant treatment in early-stage oral cavity squamous cell carcinoma: An international collaborative study. Cancer 2018;124:2948-55.

8. Almangush A, Bello IO, Keski-Santti H, et al. Depth of invasion, tumor budding, and worst pattern of invasion: prognostic indicators in early-stage oral tongue cancer. Head Neck 2014;36:811-8.

9. Almangush A, Bello IO, Coletta RD, et al. For early-stage oral tongue cancer, depth of invasion and worst pattern of invasion are the strongest pathological predictors for locoregional recurrence and mortality. Virchows Arch 2015;467:39-46.

10. Sharma P, Shah SV, Taneja C, et al. A prospective study of prognostic factors for recurrence in early oral tongue cancer. J Clin Diagn Res 2013;7:2559-62.

11. Yang $X$, Tian $X, W u K$, et al. Prognostic impact of perineural invasion in early stage oral tongue squamous cell carcinoma: Results from a prospective randomized trial. Surg Oncol 2018;27:123-8.

12. Katz O, Nachalon Y, Hilly O, et al. Radiotherapy in early- 
stage tongue squamous cell carcinoma with minor adverse features. Head Neck 2017;39:147-50.

13. Rusthoven K, Ballonoff A, Raben D, et al. Poor prognosis in patients with stage I and II oral tongue squamous cell carcinoma. Cancer 2008;112:345-51.

14. Rajappa SK, Ram D, Bhakuni YS, et al. Survival benefits of adjuvant radiation in the management of early tongue cancer with depth of invasion as the indication. Head Neck 2018;40:2263-70.

15. Dik EA, Willems SM, Ipenburg NA, et al. Resection of early oral squamous cell carcinoma with positive or close margins: relevance of adjuvant treatment in relation to local recurrence: margins of $3 \mathrm{~mm}$ as safe as $5 \mathrm{~mm}$. Oral Oncol 2014;50:611-5.

16. Chen TC, Wang CP, Ko JY, et al. The impact of pathologic close margin on the survival of patients with early stage oral squamous cell carcinoma. Oral Oncol 2012;48:623-8.

17. Kurita H, Nakanishi Y, Nishizawa R, et al. Impact of different surgical margin conditions on local recurrence of

doi: $10.21037 /$ tro.2020.01.02

Cite this article as: Cheng HS, Liu SA, Lin JC. Survival outcome and prognostic factor analyses in early tongue cancer patients treated with surgery alone. Ther Radiol Oncol 2020;4:7. oral squamous cell carcinoma. Oral Oncol 2010;46:814-7.

18. Vered M, Dayan D, Dobriyan A, et al. Oral tongue squamous cell carcinoma: recurrent disease is associated with histopathologic risk score and young age. J Cancer Res Clin Oncol 2010;136:1039-48.

19. Kligerman J, Lima RA, Soares JR, et al. Supraomohyoid neck dissection in the treatment of T1/T2 squamous cell carcinoma of oral cavity. Am J Surg 1994;168:391-4.

20. D'Cruz AK, Vaish R, Kapre N, et al. Elective versus Therapeutic Neck Dissection in Node-Negative Oral Cancer. New England Journal of Medicine 2015;373:521-9.

21. Cao Y, Wang T, Yu C, et al. Elective Neck Dissection Versus Wait-and-Watch Policy for Oral Cavity Squamous Cell Carcinoma in Early Stage: A Systematic Review and Meta-Analysis Based on Survival Data. J Oral Maxillofac Surg 2019;77:2154-67.

22. Gane EM, Michaleff ZA, Cottrell MA, et al. Prevalence, incidence, and risk factors for shoulder and neck dysfunction after neck dissection: A systematic review. Eur J Surg Oncol 2017;43:1199-218. 